\title{
Pustulosis exantemática generalizada aguda asociada a Mycoplasma pneumoniae: reporte de un caso
}

\author{
Cristián Navarrete-Dechent, Maximiliano Curi-Tuma, Catherina Moll-Manzur, \\ M. Teresa Dossi, Juan J. Manríquez, Sergio González y Félix Fich
}

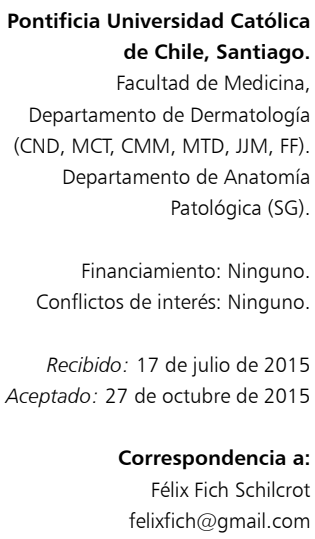

Pontificia Universidad Católica de Chile, Santiago. Facultad de Medicina Departamento de Dermatología (CND, MCT, CMM, MTD, JJM, FF). Departamento de Anatomía Patológica (SG).

Financiamiento: Ninguno. Conflictos de interés: Ninguno.

Recibido: 17 de julio de 2015 Aceptado: 27 de octubre de 2015

Correspondencia a: Félix Fich Schilcrot felixfich@gmail.com

\section{Acute generalized exanthematous pustulosis associated with Mycoplasma pneumoniae infection: a case report}

Acute generalized exanthematous pustulosis is an uncommon skin eruption, characterized by fever and the rapid onset of disseminated, non-follicular, sterile pustules, over an erythematous skin background. It is usually classified as a severe cutaneous adverse drug reaction, whose most relevant triggers are antibiotics and anticonvulsants. However, viral and bacterial infections have also rarely been associated with this dermatosis. We report the case of a patient, who developed lesions of acute generalized exanthematous pustulosis as an extrapulmonary manifestation of Mycoplasma pneumoniae infection.

Key words: Acute generalized exanthematous pustulosis, drug eruptions, Mycoplasma pneumoniae.

Palabras clave: Pustulosis exantemática generalizada aguda, erupciones medicamentosas, reacciones adversas a medicamentos, Mycoplasma pneumoniae.

\section{Introducción}

a pustulosis exantemática generalizada aguda (PEGA) es una de las reacciones adversas a medicamentos cutáneas graves (RAM). De forma infrecuente se ha asociado a agentes infecciosos, virales y bacterianos. Presentamos un caso clínico de PEGA asociado a una infección por Mycoplasma pneumoniae, en el cual los síntomas respiratorios en conjunto con la aparición del rash cutáneo resultaron en una importante clave diagnóstica.

\section{Caso clínico}

Mujer de 49 años, sin antecedentes médicos de importancia ni consumo de medicamentos recientes. Consultó por tos seca de 5 días de evolución, asociada a odinofagia y lesiones pruriginosas en los muslos. Se diagnosticó una faringoamigdalitis aguda con una escarlatina y se inició tratamiento con lincomicina oral, sin mejoría de la sintomatología ni remisión de las lesiones cutáneas. A las 48 h, se agregó fiebre hasta $38,5^{\circ} \mathrm{C}$ y las lesiones se diseminaron en forma centrípeta, por lo que consultó nuevamente. La paciente estaba en regulares condiciones generales, hemodinámicamente estable. Al examen físico, presentaba un leve eritema faríngeo asociado a un examen pulmonar normal. No se pesquisaron adenopatías. En el examen cutáneo, destacaban máculas y pápulas eritematosas palmoplantares y pústulas no foliculares, de base eritematosa, confluentes en placas, localizadas en cuello, dorso, región lumbar y muslos (Figuras 1 A y B). El signo de Nikolsky era negativo. No tenía compromiso de la mucosa oral, ocular ni genital. Sin embargo, dado el compromiso cutáneo extenso, se decidió su internación.

Los exámenes de laboratorio mostraron una leucocitosis (15.500 neutrófilos $/ \mathrm{mm}^{3}$, sin eosinofilia), proteína $\mathrm{C}$ reactiva de $14,7 \mathrm{mg} / \mathrm{dL}$ (valor normal $<1 \mathrm{mg} / \mathrm{dL}$ ) y pruebas hepáticas levemente alteradas: GOT: $23 \mathrm{UI} / \mathrm{L}$ (VN 9-25), GPT: $48 \mathrm{UI} / \mathrm{L}$ (VN 7-30), fosfatasas alcalinas: 199 UI/L (VN 30-100), GGT: 110 UI/L (VN 4-50). La radiografía de tórax mostró escaso infiltrado intersticial, sin focos de consolidación. El panel viral respiratorio molecular, por técnica de reacción de polimerasa en cadena (RPC), fue negativo. La IgM para M. pneumoniae (técnica cualitativa por ELISA) fue positiva al segundo día de hospitalización (correspondiente al noveno día de evolución). Las serologías para VIH, virus hepatitis B, C, y sífilis fueron negativas. La tinción de Gram y el cultivo corriente de las pústulas fueron negativos. Se realizó una biopsia de piel en que el estudio histopatológico mostró acantosis, espongiosis, exocitosis de neutrófilos y pústulas intracórneas, intraepidérmicas e intrafoliculares. La dermis presentaba un infiltrado perivascular difuso con linfocitos y neutrófilos (Figura 2). La tinción de PAS fue negativa para microorganismos. Dado estos hallazgos clínicos e histopatológicos, se diagnosticó una PEGA, probablemente causada por $M$. pneumoniae. Se inició tratamiento con hidrocortisona i.v., a dosis de $50 \mathrm{mg}$ fraccionada cada $8 \mathrm{~h}$, y levofloxacina oral $400 \mathrm{mg}$ al día, 


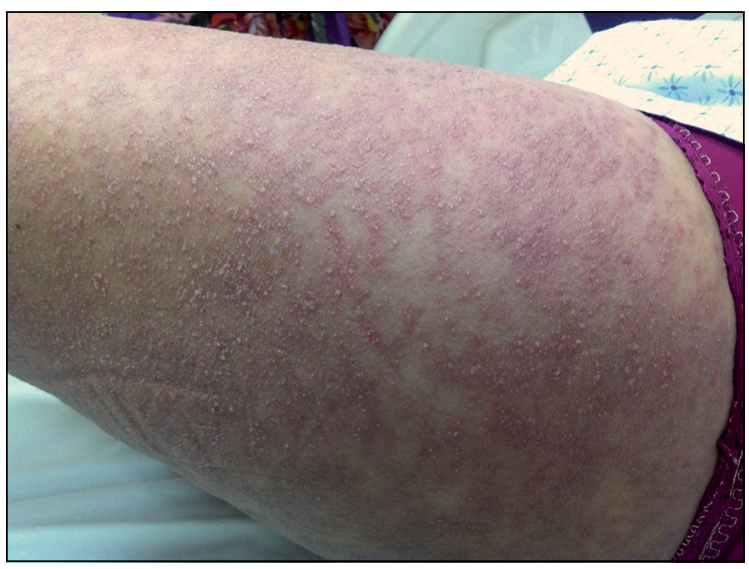

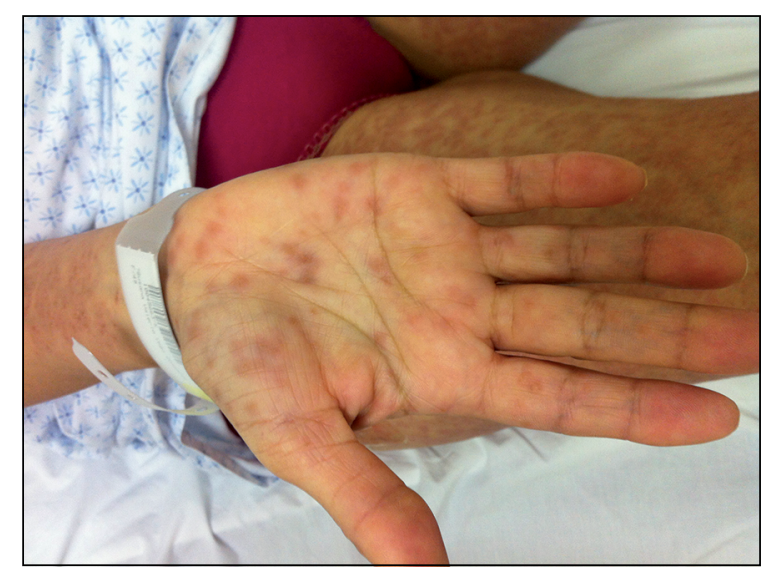

Figura 1. Presentación clínica. A: Múltiples pústulas foliculares sobre una base de eritema, localizadas en los muslos. B: Máculas y pápulas eritematosas palmares. con excelente evolución marcada por la desaparición de la fiebre y disminución de las lesiones cutáneas, dándose de alta a las $48 \mathrm{~h}$ con prednisona en dosis decrecientes y el mismo antimicrobiano, ambos por 7 días más. Al control de las dos semanas, ya no presentaba lesiones en la piel.

\section{Discusión}

Mycoplasma pneumoniae es una bacteria atípica, que comúnmente causa infecciones respiratorias tanto en población pediátrica como adulta. Pese a que la mayoría son leves, las complicaciones extrapulmonares son relativamente frecuentes. Se estima que 25 a $33 \%$ de los pacientes infectados presentan alguna forma cutánea de la enfermedad, aún cuando no se manifieste clínicamente la neumonía ${ }^{1}$. Estas manifestaciones cutáneas pueden ser leves y con resolución espontánea, o letales.

Los síntomas prodrómicos de la infección por $M$. pneumoniae aparecen generalmente una semana previa a la erupción cutánea. Estos síntomas son inespecíficos e incluyen tos, debilidad y fiebre ${ }^{2}$. El diagnóstico de la infección aguda por $M$. pneumoniae se realiza con técnicas serológicas ( $\operatorname{IgM})$, RPC o cultivos. Las técnicas serológicas (como la realizada en este caso) son las más usadas, pero se asocian a una alta tasa de falsos positivos por reacciones cruzadas o en períodos de alza epidémica (especificidad diagnóstica tan baja como 49\%, según algunos estudios); además, tardan 7-10 días en hacerse $\operatorname{positivos}^{3-5}$. La RPC de muestra respiratoria es superior a la serología y es positiva de manera precoz ${ }^{4}$. Lamentablemente, no se pudo contar con el estudio con RPC en nuestro paciente.

Las patologías cutáneas más frecuentes asociadas a $M$. pneumoniae son la erupción exantemática maculopapular $(8-33 \%)$, el eritema nodoso (8\%), la urticaria (7\%), el eritema multiforme y el síndrome de Steven-Johnson/

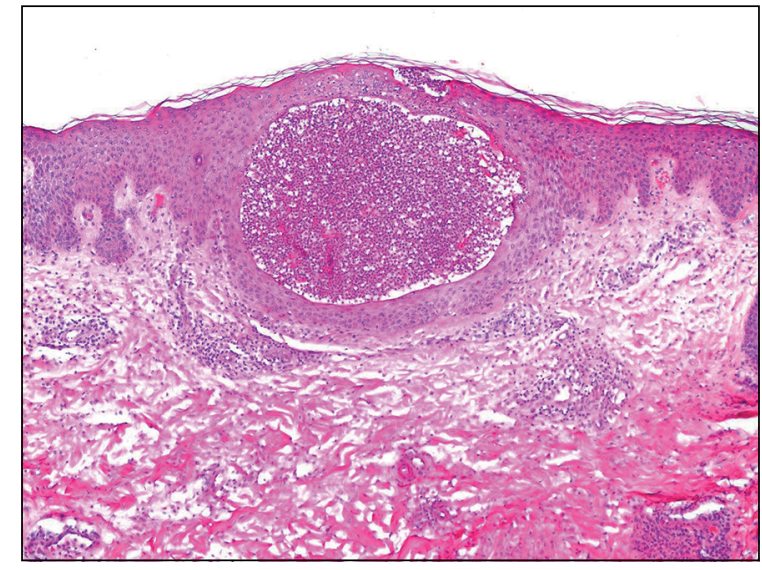

Figura 2. Microfotografía que muestra una gran pústula intraepidérmica y una pequeña pústula intracórnea con infiltración linfocitaria y neutrofílica perivascular e intersticial. (Tinción H\&E, 80X). necrólisis tóxica epidérmica (SJS/NET) ${ }^{1}$. Existen en la literatura especializada además, comunicaciones de casos que asocian a $M$. pneumoniae con otras enfermedades cutáneas, resaltando su rol como el "gran simulador" tanto en patología respiratoria como cutánea. En el caso de la PEGA, sólo existe un caso reportado asociado a infección por M. pneumoniae 6 . El hallazgo adicional de una RPC positiva para $M$. pneumoniae podría haber hecho más estrecha la relación causa-efecto en nuestro paciente. Por otro lado, parece poco probable que el cuadro haya sido causado por el antimicrobiano (lincomicina oral) debido a que las lesiones ya habían comenzado al momento de la administración de este fármaco.

La PEGA es una patología de baja incidencia (1-5 casos/millón/año), catalogada como una RAM, aunque en un porcentaje pequeño, se ha asociado a infección por agentes virales y menos frecuentemente bacterianos, al igual que el SJS/NET ${ }^{7,8}$.

Los medicamentos con asociación comprobada a PEGA se resumen en la Tabla 1 y son los responsables de 


\begin{tabular}{|l|}
\hline Tabla 1. Medicamentos asociados a PEGA \\
\hline Antimicrobianos \\
- Pristinamicina \\
- Aminopenicilinas \\
- Quinolonas \\
- Macrólidos \\
- Sulfas \\
Antimicóticos \\
- Terbinafina \\
Anticonvulsivantes (excepto ácido valproico) \\
Antihipertensivos \\
- Diltiazem \\
Paracetamol \\
Antiinflamatorios \\
- No esteroidales \\
- Corticoides
\end{tabular}

$90 \%$ de los $\operatorname{casos}^{9}$. El lapso entre la exposición al fármaco y PEGA varía desde horas hasta una a dos semanas, clásicamente siendo 48 a 72 h desde la introducción del fármaco ${ }^{9-11}$. Particularmente para los antimicrobianos, se ha descrito que el período de latencia suele ser menos de $24 h^{9}$.

Los agentes infecciosos asociados a PEGA incluyen los virus miembros de la familia Enteroviridae (coxsackie B4), citomegalovirus, parvovirus B19, virus de EpsteinBarr, así como, el virus de la hepatitis B, Chlamydia pneumoniae, las infecciones urinarias crónicas por Escherichia coli y anecdóticamente M. pneumoniae ${ }^{8,10}$.

Tabla 2. Diagnóstico diferencial de PEGA

Enfermedades que pueden presentarse con pustulosis folicular:

- Foliculitis infecciosas (bacterianas o fúngicas principalmente)

- Erupciones acneiformes

Exantemas virales

Reacciones adversas a medicamentos (en las etapas pre-pustulares de la PEGA):

- Síndrome de SIS/NET

Síndrome de DRESS

Psoriasis pustular generalizada con compromiso sistémico (von Zumbusch)

Dermatosis pustular subcórnea (Síndrome de Sneddon-Wilkinson)

Vasculitis pustular (como el Behçet)

Pustulosis amicrobiana de las flexuras
La PEGA se inicia clásicamente con fiebre sobre $38^{\circ} \mathrm{C}$, acompañada luego por la aparición de cientos de pústulas pequeñas $(<5 \mathrm{~mm})$, estériles, no foliculares, sobre una base de eritema y edema. Es más acentuado y suele comenzar en la cara y en los pliegues, para luego generalizarse en horas al tronco y los muslos ${ }^{8,12}$. Puede existir además edema facial, prurito o sensación de ardor. Habitualmente no afecta mucosas, aunque pudiera hacerlo hasta en $20 \%$ de los casos, con manifestaciones leves y restringidas a la mucosa oral ${ }^{7,8}$. De forma extremadamente infrecuente, se ha descrito conjuntivitis ${ }^{13}$.

En los hallazgos de laboratorio destaca la leucocitosis (con neutrofilia en la mayoría de los casos, pudiendo asociarse a eosinofilia en $30 \%$ de los pacientes $)^{7,8}$. El compromiso visceral ocurre en menos de $20 \%$ de los casos ${ }^{13}$. La mayoría de las veces se manifiesta con el aumento de las aminotransferasas o la disminución del aclaramiento de creatinina (en ocasiones con insuficiencia renal) ) $^{8,12,13}$. No debe esperarse compromiso de otros órganos, si bien en casos muy raros se ha visto PEGA con falla hepática, distrés respiratorio y agranulocitosis ${ }^{13}$. La evidencia disponible sugiere que amoxicilina es el fármaco que más se asocia a PEGA con compromiso sistémico ${ }^{13}$.

El estudio microbiológico de una muestra de raspado de las pústulas es negativo. La histopatología de la PEGA muestra pústulas espongiformes subcórneas y/o intraepidérmicas con edema de la dermis papilar e infiltrado perivascular de predominio neutrofílico ${ }^{7,12}$.

Respecto a la fisiopatología de la PEGA, se ha evidenciado la presencia de linfocitos T CD8 específicos a ciertos fármacos en etapas iniciales, induciendo apoptosis de queratinocitos y formación de vesículas intraepidérmicas. Posteriormente, hay presencia de linfocitos T CD4 que secretan CXCL-8, lo cual recluta neutrófilos convirtiendo las vesículas en pústulas. Los linfocitos T CD4 secretan además IFN $\gamma$ que induce a los queratinocitos a secretar más CXCL-8, traduciéndose en quemotaxis adicional de neutrófilos ${ }^{8}$. En el caso de las etiologías infecciosas no existe un mecanismo fisiopatológico claro; sin embargo, nosotros planteamos la hipótesis que algunos antígenos de $M$. pneumoniae podrían producir reacciones cruzadas con antígenos de fármacos, funcionar como haptenos o de manera sinérgica con algunos medicamentos desencadenando la misma reacción inmunológica que en la PEGA clásica.

El diagnóstico diferencial de la PEGA es amplio (Tabla 2); sin embargo, de especial consideración, se encuentran otras RAM, entre las cuales destacamos:

- Síndrome de Steven-Johnson/necrolisis epidérmica tóxica: Suele presentarse con fiebre y síntomas tipo influenza, asociados a máculas eritematosas con centros purpúricos o como un eritema difuso, que progresa a vesículas y bulas. En más de $90 \%$ de los casos compromete la mucosa oral, manifestándose como erosiones 
hemorrágicas ${ }^{14}$. En general, es fácil la distinción entre ambos cuadros dado el compromiso cutáneo-mucoso más profundo de SJS/NET, aunque en casos graves de PEGA, la confluencia de pústulas puede simular un falso signo de Nikolsky, que caracteriza al SJS/NET. De igual forma, en algunos casos de PEGA pueden encontrarse lesiones en diana atípicas que remedan las presentes en SJS/NET ${ }^{11,12,15}$.

- Síndrome de hipersensibilidad a medicamentos con eosinofilia y síntomas sistémicos (DRESS por su acrónimo en inglés): Aunque su compromiso cutáneo clásico es un exantema máculo-papular asociado a edema facial y adenopatías; de manera ocasional puede cursar con un exantema pápulo-pustular generalizado. El compromiso visceral (hepatitis, nefritis, neumonitis, miocarditis) casi constante, junto con el antecedente de un fármaco reconocido como altamente asociado a DRESS contribuye al diagnóstico diferencial ${ }^{7,8}$.

- Escarlatina: La reacción cutánea a $S$. pyogenes mediada por super-antígenos fue considerada en la primera evaluación de este paciente. Sin embargo, la escarlatina se presenta como un exantema "áspero" caracterizado por realce folicular, palidez perioral (triángulo de Filatov), líneas de Pastia y lengua en fresa. Si bien cuando el cuadro de escarlatina está completo es fácil hacer el diagnóstico diferencial con la PEGA, en un principio puede ser difícil ya que ambas enfermedades se inician con compromiso de pliegues.

De manera adicional, se han descrito presentaciones atípicas graves de PEGA; éstas han sido mencionadas como la sobreposición entre PEGA y NET o con DRESS, pudiendo presentarse con un curso clínico similar a estas entidades (incluyendo el compromiso sistémico grave) pero con histopatologías compatibles con PEGA ${ }^{10}$.

Existe un score de diagnóstico validado para la PEGA realizado por el grupo EuroSCAR (European study of severe cutaneous adverse reactions), que incluye criterios morfológicos, evolutivos e histopatológicos y que puede ser de utilidad para el enfrentamiento diagnóstico (Tabla $3)^{12}$.

No existen guías basadas en la evidencia que orienten en el manejo de la PEGA. Sin embargo, dado que típicamente presenta una resolución espontánea y un curso favorable, el tratamiento es por naturaleza, de soporte. La medida más importante es la suspensión del fármaco causal y con ello, habitualmente la resolución del compromiso cutáneo e incluso sistémico ocurre en menos de 15 días $^{13}$. En la fase pustular pueden usarse apósitos húmedos con soluciones antisépticas tópicas, mientras que en la fase descamativa (post-pustular) los emolientes podrían optimizar la función de barrera. No existe evidencia que los corticoesteroides tópicos o sistémicos aceleren la resolución de la enfermedad; sin
Tabla 3. Score diagnóstico validado para PEGA (modificado de $[4,9]$ )

\begin{tabular}{|c|c|c|}
\hline Criterio & Observación & Puntuación \\
\hline \multicolumn{3}{|l|}{ 1) Morfología: } \\
\hline \multirow[t]{3}{*}{ Pústulas } & Típica & +2 \\
\hline & Consistente* & +1 \\
\hline & Insuficiente** & 0 \\
\hline \multirow[t]{3}{*}{ Eritema } & Típica & +2 \\
\hline & Consistente* & +1 \\
\hline & Insuficiente** & 0 \\
\hline \multirow[t]{3}{*}{ Patrón de distribución } & Típica & +2 \\
\hline & Consistente* & +1 \\
\hline & Insuficiente** & 0 \\
\hline \multirow[t]{2}{*}{ Descamación post-pustular } & Sí & +1 \\
\hline & No/Insuficiente** & 0 \\
\hline \multicolumn{3}{|l|}{ 2) Curso: } \\
\hline \multirow[t]{2}{*}{ Compromiso de mucosas } & Sí & -2 \\
\hline & No & 0 \\
\hline \multirow[t]{2}{*}{ Inicio agudo ( $\leq 10$ días) } & Sí & 0 \\
\hline & No & -2 \\
\hline \multirow[t]{2}{*}{ Resolución en $\leq 15$ días } & Sí & 0 \\
\hline & No & -4 \\
\hline \multirow[t]{2}{*}{ Fiebre $\geq 38^{\circ} \mathrm{C}$} & Sí & +1 \\
\hline & No & 0 \\
\hline \multirow[t]{2}{*}{ Recuento de neutrófilos $>7.000 / \mathrm{mL}$} & Sí & +1 \\
\hline & No & 0 \\
\hline \multicolumn{3}{|l|}{ 3) Histología: } \\
\hline \multicolumn{2}{|l|}{ Sugerente de otra enfermedad } & -10 \\
\hline \multicolumn{2}{|l|}{ No representativa/sin histología } & 0 \\
\hline \multicolumn{2}{|l|}{ Con exocitosis de neutrófilos periféricos } & +1 \\
\hline \multicolumn{2}{|c|}{$\begin{array}{l}\text { Pústulas subcórneas y/o intraepidérmicas con/sin espongiosis o pústulas } \\
\text { (sin mayor especificación) con/sin edema papilar }\end{array}$} & +2 \\
\hline \multicolumn{2}{|c|}{ Pústulas espongióticas, subcórneas o intraepidérmicas con edema papilar } & +3 \\
\hline
\end{tabular}

embargo, los tópicos pueden ser considerados para aliviar los síntomas, mientras que los sistémicos en pacientes con lesiones extensas con/sin compromiso de órganos internos $^{8}$. En aquellos casos de PEGA que simula NET se ha usado incluso inmunoglobulina intravenosa. Por ello, el tratamiento debiese reflejar la extensión de los síntomas sistémicos y el grado de sospecha clínica ${ }^{9}$.

En el caso de las manifestaciones mucocutáneas por $M$. pneumoniae, el uso de antimicrobianos como tetraciclinas, macrólidos y fluoroquinolonas no está demostrado que acorte el curso ni la gravedad de las manifestaciones mucocutáneas $^{2,16}$. Pese a que levofloxacina no es el antibacteriano de elección para el tratamiento de $M$. pneumoniae, lo elegimos debido a que los macrólidos 
son una de las principales causas de PEGA, por lo que no quisimos exponer a la paciente a este riesgo.

Finalmente, el pronóstico de esta enfermedad es bueno, aún cuando haya compromiso sistémico. Se ha estimado una tasa de mortalidad de 5\%, pudiendo ser menor debido a escasez de datos epidemiológicos confiables ${ }^{7,13}$.

En resumen, el diagnóstico de PEGA debe ser considerado siempre en los rash de tipo pustulares y deberá buscarse en primer lugar el fármaco que pudiera causarla ( $90 \%$ de asociación). En aquellos casos en los cuales no se pesquise o no se sospeche la presencia de un medicamento, se debe iniciar una búsqueda de agentes infecciosos. El conocimiento de los hallazgos y del curso clínico usualmente favorable de la enfermedad, contribuyen a prevenir el uso de medidas terapéuticas, muchas veces innecesarias.

\section{Referencias bibliográficas}

1.- Schalock P C, Dinulos J G. Mycoplasma pneumoniae-induced cutaneous disease. Int $\mathrm{J}$ Dermatol 2009; 48: 673-80.

2.- Canavan T N, Mathes E F, Frieden I, Shinkai K. Mycoplasma pneumoniae-induced rash and mucositis as a syndrome distinct from StevensJohnson syndrome and erythema multiforme: a systematic review. J Am Acad Dermatol 2015; 72: 239-45.

3.- $\quad$ Lim C S, Lim S L. Acute generalized exanthematous pustulosis associated with asymptomatic Mycoplasma pneumoniae infection. Arch Dermatol 2009; 145: 848-9.

4.- Paulmann M, Mockenhaupt M. Severe drug-induced skin reactions: clinical features, diagnosis, etiology and therapy. J Dtsch Dermatol Ges 2015; 13: 625-45.
5.- Fernando S L. Acute generalised exanthematous pustulosis. Australas J Dermatol 2012; 53: 87-92.

6.- Sidoroff A, Dunant A, Viboud C, Halevy S, Bavinck J N, Naldi L, et al. Risk factors for acute generalized exanthematous pustulosis (AGEP)-results of a multinational case-control study (EuroSCAR). Br J Dermatol 2007; 157: 989-96.

7.- Kostopoulos T C, Krishna S M, Brinster N K, Ortega-Loayza A G. Acute generalized exanthematous pustulosis: atypical presentations and outcomes. J Eur Acad Dermatol Venereol 2015; 29: 209-14.

8.- Paradisi A, Bugatti L, Sisto T, Filosa G, Amerio P L, Capizzi R. Acute generalized exanthematous pustulosis induced by hydroxychloroquine: three cases and a review of the literature. Clin Ther 2008; 30: 930-40.

9.- Sidoroff A, Halevy S, Bavinck J N, Vaillant L,
Roujeau J C. Acute generalized exanthematous pustulosis (AGEP)-a clinical reaction pattern. J Cutan Pathol 2001; 28: 113-9.

10.- Hotz C, Valeyrie-Allanore L, Haddad C, Bouvresse S, Ortonne N, Duong T A, et al. Systemic involvement of acute generalized exanthematous pustulosis: a retrospective study on 58 patients. Br J Dermatol 2013; 169 (6): 1223-32.

11.- Roujeau J C, Stern R S. Severe adverse cutaneous reactions to drugs. N Engl J Med 1994; 331: 1272-85.

12.- Bachot N, Roujeau J C. Differential diagnosis of severe cutaneous drug eruptions. Am J Clin Dermatol 2003; 4: 561-72.

13.- Terraneo L, Lava S A, Camozzi P, Zgraggen L, Simonetti G D, Bianchetti M G, et al. Unusual eruptions associated with Mycoplasma pneumoniae respiratory infections: review of the literature. Dermatology 2015; 231: 152-7. 